\title{
The key role of causal explanation in the climate change issue
}

\author{
Francesca PONGIGLIONE
}

Received: 21.10 .2011

Final version: 7.3.2012

BIBLID [0495-4548 (2012) 27: 74; pp. 175-188]

ABSTRACT: In the context of climate change, the adoption of pro-environment behaviour is favoured by the understanding of causal passages within climate science. The understanding of the causes of climate change is necessary in order to be able to take mitigation actions (the subject needs to be aware of its role as a causal agent). Conversely, the understanding of the consequences of climate change is essential for rationally managing the risks, especially in cases where adaptation is needed rather than simple mitigation. The case of ozone depletion confirms this view: the understanding of its causal dynamics played a major role in people's behavioural response.

Keywords: climate change; knowledge; causal explanation.

RESUMEN: Para afrontar el cambio climático, la adopción de un comportamiento en favor del medio ambiente se verá favorecida por la comprensión de los argumentos causales de la climatología. La comprensión de las causas del cambio climático es necesario para que seamos capaces de mitigarlo (cada individuo debe ser consciente de su papel como agente causal). La comprensión de las consecuencias del cambio climático es esencial para gestionar racionalmente los riesgos, especialmente en casos en los que más que mitigarlo, debemos intentar adaptarnos. El caso del agujero de la capa de ozono confirma este punto de vista: la comprensión de la dinámica causal desempeñó un papel principal en el cambio de conductas de la gente.

Palabras clave: cambio climático; conocimiento; explicación causal

\section{Introduction}

Tackling climate change has been considered for years a problem that policy makers were supposed to solve through an international agreement that imposed limits on CO2 emissions. This task has proven to be, throughout the years, one of the most difficult challenges that the international community has ever been called to face because of the number of ethical, political and economic issues it raises. It is now clear that the success of the Montreal Protocol ${ }^{1}$ for tackling ozone depletion may not be replicated anytime soon.

As the process of reaching a binding agreement on emission caps is still ongoing, psychologists and behavioural scientists have started giving increasing attention to the role of individual behaviour. Although individual action might seem irrelevant to a global issue such as climate change, there are a number of good reasons for not underestimating its weight. Above all, its importance is borne out by the International Energy Agency's data on CO2 emissions in OECD countries ${ }^{2}: 19,7 \%$ of emissions de-

${ }^{1}$ See Montreal Protocol On Substances that Deplete the Ozone Layer, United Nations Environment Programme, 2010. 2010 Assessment Report of the Halons Technical Options Committee. Available at: http://ozone.unep.org/Assessment_Panels/TEAP/Reports/HTOC/index.shtml

${ }^{2}$ Data on emissions with electricity and heat allocated to consuming sectors (IEA 2010). 
rive from residential consumption, and $23,7 \%$ from road transport. These numbers are per se good reasons to start reconsidering the role of individual actions in contributing to climate change, and therefore its potential in tackling it.

Different elements influence the decision process that leads individuals to adopt pro-environment behaviour: personal values, attitudes and moral norms, risk perception and knowledge among many others. Each of these elements is important, and none of them by themselves seem to hold the key for a behavioural change. In this essay I will take into account the role of knowledge, and more specifically, of a particular form of knowledge: the understanding of causal explanations, that, as I suggest here, seems to be essential for giving rise to a behavioural response. As Figure 1 below shows, people need to be aware of (1) their role as causal agents who through their daily actions contribute significantly to the environmental crisis and (2) of the consequences that climate change is likely to have on human life, i.e., of the risks raised by it. In other words, people need to understand some basic causal relations within climate dynamics, in order to know, concretely, how to take mitigation actions. Furthermore, understanding the negative consequences that climate change will have on humans provides a strong motivation for taking preventive action.

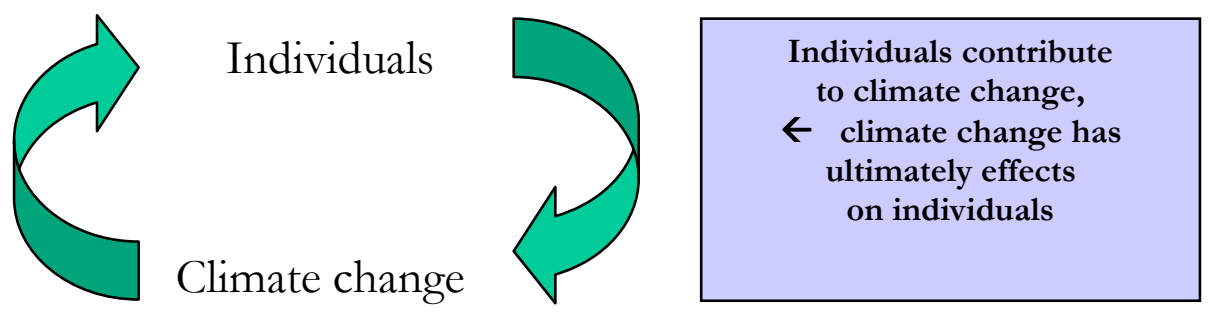

Figure 1: Individuals and climate change

Last but not least, understanding their role as causal agents in regard to a specific issue, makes people also ethically responsible for their actions - if I do not know which consequences my actions give rise to, I do not feel personally responsible for the possible damage they might cause. But if, on the other hand, I am aware of the impact of my behaviour, and consequently I am able to identify a right and a wrong behaviour, I am also morally responsible for any wrongdoing.

\section{Understanding the causes of climate change}

The increased media coverage of climate change in the past twenty years has produced a high level of awareness and concern, in both Europe and the United States (Eurobarometer 2009a; Leiserowitz et al. 2010b). According to recent surveys (Eurobarometer 2009a; Leiserowitz et al. 2010b), most people in Europe and in the United States consider themselves to be fairly well informed (51\% in the US, $47 \%$ in the EU) or very well informed (11\% in the US, $9 \%$ in the EU) about climate change. Furthermore, only few people in Europe $(10 \%)$ consider climate change not to be a serious problem (Eurobarometer 2009a); and in the US 55\% of survey's respondents declare to be ei- 
ther very worried or somewhat worried about global warming (Leiserowitz et al. 2010b). These high percentages of concerned people to some extent tell us that the atmosphere of uncertainty that surrounds the media coverage of climate science has not translated in an overall scepticism about its seriousness - which is quite surprising, if one considers the high occurrence of misleading or simply wrong information spread through news sources (Boykoff and Rajan 2007). It might well be, as suggested by Stamm, Clark and Eblacas (2000) that public attention on an environmental problem tends to follow the quantity of media coverage, regardless of the content of the communicated information (p. 220).

Instead, what is surprising is the poor level of concrete knowledge about basic climate science that more precise surveys have reported: $42 \%$ of US people do not know which gases are responsible for increasing the Earth's surface temperature (Leiserowitz et al. 2010b), and 31\% of Europeans think that CO2 emissions and other greenhouse gases have only a marginal impact on climate change, with $12 \%$ of "don't know" responses (Eurobarometer 2009a). Apparently, there is no consistency between self-reported and actual knowledge about climate change, despite the high level of awareness and concern which is likely due to increasing media coverage. Climate change has in fact become, over the years, a hot media topic: just in the UK newspaper coverage of climate change from 1988 to 2006 has gone from less that 250 articles per year to over 2000 articles (survey conducted on The Guardian, The Independent, The Times by Boykoff and Rajan 2007).

That media coverage does not generate knowledge ${ }^{3}$ is well documented by a number of studies (Ungar 2000, Wilson 2000, Boykoff and Rajan 2007). First, many journalists deal with the climate change issue as, primarily, an economic issue; others debate the degree of uncertainty that surrounds climate science; and still others treat climate science as a matter of political opinion or mere international relations. The result is that among the thousands of articles published on climate change, very few of them actually explain what climate change is, how it is generated and what consequences it is likely to bring about. These basic causal relations within climate dynamics are not easily understandable nor intuitive, but require, instead, a specific effort of science communicators and journalists in order to be clarified.

We could identify some essential facts that need to be comprehended in order to be able to understand one's role as causal agent:

1. Climate change is caused by an over-accumulation of greenhouse gases in the atmosphere (mainly $\mathrm{CO} 2$ )

2. $\mathrm{CO} 2$ is produced by the combustion of fossil fuels (mainly oil, coal and gas)

\footnotetext{
${ }^{3}$ Also the role of the media as a good means of risk communication is debated. As suggested by Wåhlberg and Sjöberg (2000), the media are not always considered a reliable source of information, and people trust more direct information about risks (e.g. from people who have experienced them), rather than such an "impersonal" mean of communication.
} 
3. Electricity, heat production and transport are the fundamental sources of $\mathrm{CO} 2$ emissions from fossil fuel combustion $(66 \%$ of total emissions in OECD countries - IEA 2010).

The understanding of these basic facts, although not sufficient for inducing a behavioural change, is however a conditio sine qua non for the understanding of the relevance of some "preventive" or "mitigation" actions that the individual can take for tackling climate change that include: significant reductions in the consumption of electricity, air conditioning and heating, car use and the consumption of imported and non-seasonal food. Despite their overall simplicity, the adoption of these kinds of behaviours could lead to a meaningful reduction in emissions.

Climate dynamics leading to global warming cannot be obviously reduced to the three points mentioned above. However, as figure 2 below shows, the series of causal relations leading to the rise of the temperature of the Earth (starting from some human activities that are relevant in the production of greenhouse gases) is very long and not intuitive.

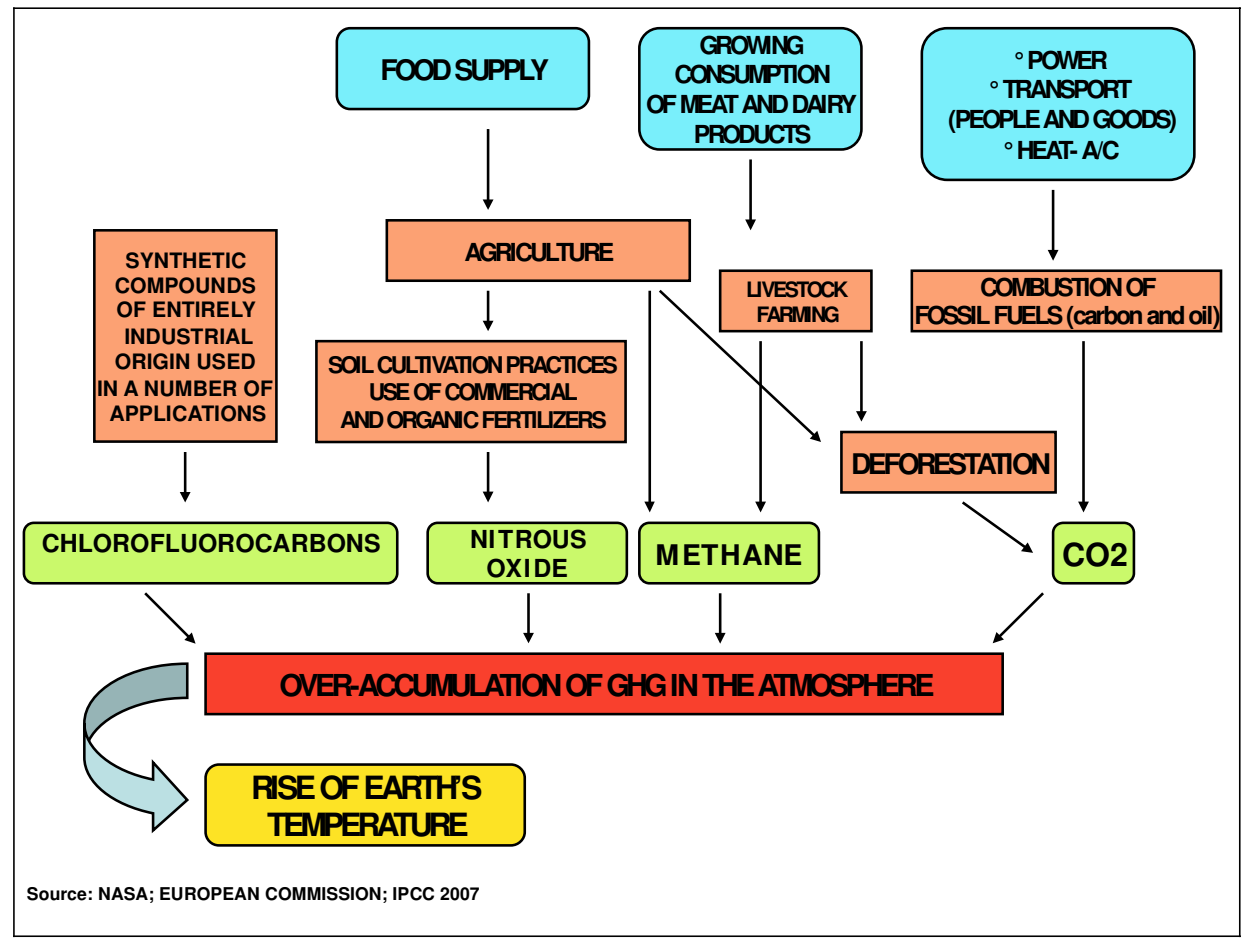

Figure 2: Dynamics that lead to global warming

For instance, that the consumption of meat contributes to global warming is something that would require a careful explanation through causal passages, since it is not immediately intuitive; and the same could be said for the consumption of non- 
seasonal or imported food, that implies transport from long distances, with its consequent amount of $\mathrm{CO} 2$ emissions.

\section{Behavioural consequences of lack of understanding of causes of climate change}

Individuals' declared willingness to undertake personal action to fight climate change is, in both Europe and the US, quite encouraging. In Europe, 63\% of interviewees declare to have already started taking action on climate change (Eurobarometer 2009a), and in America surveys on the adoption of specific behaviour show that a good percentage of people are trying to modify some of their habits (Leiserowitz et al. 2010c). Specifically, $78 \%$ of Europeans and $56 \%$ of Americans are separating waste for recycling; $63 \%$ of Europeans and $90 \%$ of Americans try to reduce energy consumption at home (by turning off, for instance, unneeded lights) (Eurobarometer 2009a, Leiserowitz et al. 2010c).

Although the data above suggest, at the very least, that people are more conscious of their behaviour, much remains to be done. On the one hand people appear to be willing to do something for the environment; however, with respect to actions having a stronger impact on the environment, the observed behavioural change is still not enough. In Europe, only 18\% of total survey respondents have chosen an environmentally friendly way of transportation (by foot, bicycle, public transport), and just $15 \%$ have reduced car use (for example by car-sharing or using cars more efficiently) (Eurobarometer 2009a). In the United States, only 12\% of people use public transport or car pooling rather than their own vehicles, and $18 \%$ prefer to walk or bike rather than drive. The behavioural attitude of Americans could also be in part connected to the fact that respectively $28 \%$ and $23 \%$ of people do not think that public transport, car pooling, and walking or biking is important for the environment (Leiserowitz et al. 2010c).

It cannot be argued that those who have not personally taken action on climate change would change behaviour with a higher understanding of causal relations within climate science. But to some extent part of the problem rests also on a lack of knowledge. A 2008 Eurobarometer's survey addressed some questions specifically to people who declared not to have taken any preventive action on climate change. Among the various responses, $34 \%$ of respondents said they would like to take action but do not know what to do.

\section{Understanding the consequences of climate change}

Unclear causal relations within climate dynamics do not concern only the causes of climate change, but also its consequences. The issue is even more complex, due to the fact that the actual impact of climate change is still difficult to foresee. Moreover, knowledge about what the temperature rise may cause is not very widespread among people. And this is understandable, given the number of consequences that climate change may have, as reported by the IPCC (Figure 3).

So, what are the consequences of not understanding the possible harm caused by climate change? First, the same as not understanding its causes: if people are not 
aware of the actual damage they possibly contribute to, with their actions, they will not feel morally responsible for their behaviour. But there is something else. Understanding the consequences of climate change has also an important connection to risk perception. On the one hand, I cannot claim that if I understand the harm that climate change may cause, I will also feel personally at risk and tackling climate change will be my first concern. In fact, most of the risks above listed are long-term ones, that can hardly alarm individuals in their personal and daily dimension, given the more urgent issues that people deal with daily. And the surveys so far conducted on risk perception prove that people perceive climate change as a serious issue from a global perspective,

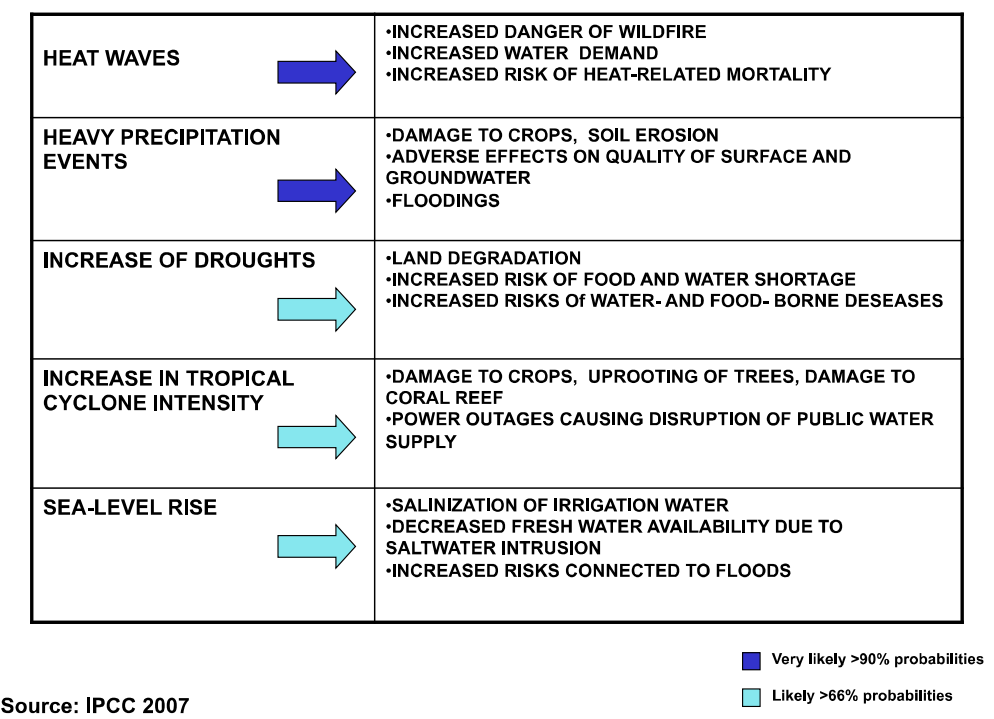

Figure 3: Likely consequences of global warming

but not from a local or personal one: in Europe, climate change is considered the second most serious problem the world is facing today, but only $4 \%$ of interviewees consider the environment to be a main concern of their own country, and $5 \%$ believe it is a problem affecting their personal lives (Eurobarometer 2009a, 2009b, 2009c); in the US, survey respondents think that global warming will not at all $(31 \%)$ or only a little $(22 \%)$ affect their personal dimension, but "a great deal" $(43 \%)$ and "a moderate amount" (19\%) plant and animal species, and "a great deal" (42\%) and "a moderate amount" (21\%) future generations (Leiserowitz et al. 2010a).

On the other hand, understanding the consequences of climate change is the only way to rationally manage the risk when it is closer, and, in case mitigation is not possible, this kind of knowledge is what allows adaptation. This fact was widely visible in a series of field studies run by anthropologists in developing world small communities 
(Crate and Nuttal 2008) where native people noticed a significant change in climate, but completely lacked knowledge about what was happening, and failed by default in managing the situation they were experiencing. Only through understanding the connection between the risk one perceives and its cause, can one try to prevent it. Simple risk perception cannot in fact be considered a strong predictor of people's behavioural response, especially if it comes with no further information on how to interact with it (and this interaction presupposes the understanding of one's role as a causal agent). Furthermore, trying to induce fear through images or fearful messages is not itself a solution, since a common reaction is a form of psychological removal as shown by O'Neill and Nicholson-Cole (2009) and also by some field studies conducted in regions affected by global warming (Strauss 2008, Norgaard 2006). The main argument of these studies is that people felt that the risk was so big that their individual actions were totally powerless, and exhibited a kind of psychological denial (Strauss 2008, Norgaard 2006).

Understanding causal dynamics leading to damage to the natural environment and consequently to humans might first help people assess the risk more rationally avoiding denial and excessive fear. Second, if the understanding of the possible consequences of climate change was more widespread, the arguments for denying its importance and urgency would be much weaker.

\section{How does knowledge affect pro-environment behaviour?}

Determining the effects of knowledge on pro-environment behavior is an issue of ongoing and vigorous academic debate. Scholars who adhere to the knowledge deficit model (Reynolds et al. 2010; Read et al. 1994) tend to be sanguine about the potential of understanding to engender changes in behavior. According to their framework, individual inaction is precisely attributable to a pre-existing lack of knowledge - in this case understood as scientific understanding (Reynolds et al. 2010; Bostrom et al. 1994; Read et al. 1994). Supporters of this decision-theoretic model argue that possession of basic information about causal relations between action and outcome is a necessary condition for action, and therefore providing people with this kind of knowledge should probably be sufficient to enact their behavioral response.

In contrast to the views of these scholars, a considerable amount of research suggests that increasing the amount of relevant information surrounding an action does not imply that this action will be automatically performed. In fact, many scholars seem to agree that, despite being a necessary element for taking action, understanding of an issue is not a strong predictor of human behavior. In the specific case of climate change, the connection between knowledge and action and/or concern seems to be particularly weak (Norgaard 2006, 2009; Strauss 2008). A recent study by Kahan et al. (2011) argues against the idea that skepticism about climate change is due to a sort of "scientific illiteracy". The authors conducted a survey with a large sample of US adults, and measured (1) their "science literacy" using a set of questions from the National Science Foundation (that did not explicitly refer to climatic issues, though) aimed at finding out their familiarity with basic science, and (2) their "numeracy", i.e. "their capacity to comprehend and use quantitative information as measured by re- 
sponses to mathematical word problems" (p. 4). Their hypothesis was that who was more at ease with scientific topics, and displayed a higher "numeracy", would have been able to correctly assess climate-change related risks, and should have shown more concern than other people. The survey's results refute this hypothesis, giving evidence of no relationship between science literacy/numeracy and environmental concern. Two reflections arise from this experiment: (a) Kahan and his colleagues' hypothesis considered a very specific kind of scientific understanding - "science literacy", which is on some level necessary, though seemingly not sufficient for grasping the problem. But when we aim to find out whether a possible relationship exists between "knowledge" and concern (or even between knowledge and action) we need to give primary importance to the fact that many different kinds of knowledge exist: from the simple awareness of the great public to the deep understanding that only scientists possess, there is a wide sphere of "intermediate" levels of knowledge that need to be considered. Kahan et al.'s "basic science", while relevant, has no specific connections with climate dynamics, and may not be a good predictor of people's concern about climate change. The second point (b) is that "understanding science" does not imply being able to deal with it in an objective way, as also Kahan and colleagues suggest in their paper, observing that greater scientific literacy is associated with greater cultural polarization. Many scientific issues (including global warming) are per se not emotionally neutral, and bring along a number of feelings such as fear, guilt, helplessness (see Norgaard 2006, 2009), against which not even scientists are immune.

The understanding of causal relations within climate dynamics seems instead a more necessary component for giving rise not simply to concern, but primarily to action. In the words of Ludwig von Mises (1963, 22-23): "Man is in a position to act because he has the ability to discover causal relations which determine change [...]. Acting requires and presupposes the category of causality. [...] In order to act, man must know the causal relationship between events, processes, or states of affairs. And only as far as he knows this relationship, can his action attain the end sought."

Nonetheless, the extent to which understanding is generally dependent upon causal explanations is a philosophical issue vigorously debated among philosophers and scientists (Salmon 1984; de Regt and Dieks 2005; Besson 2008), but it will not be discussed here. I suggest that in the case of climate change the understanding of causal passages is required for people's self-perception as actors - whose actions can produce significantly different outcomes, without claiming that acquiring this kind of knowledge is per se sufficient to generate a change in behaviour.

\section{The Orone hole issue: from understanding to action}

The Montreal Protocol on Substances that Deplete the Ozone Layer, signed on September 1987, is perhaps the most successful environmental agreement on the use and management of a common good. The Montreal Protocol established a gradual phaseout of ozone depleting substances, namely Chlorofluorocarbons, after Mario Molina and Sherwood Rowland from the University of California discovered in 1974 that CFCs released chlorine atoms under high ultraviolet radiation, and these atoms destroyed the ozone layer. 
In addition to the unexpected diplomatic success of the Montreal Protocol (see Benedick 1998), people's behavioural response to the problem of ozone depletion was equally noteworthy. This behavioural response had several reasons behind it: boycotting products based on CFCs does not require an active effort (it is simply about "not buying something"), nor does it involve any significant change of habits or a lowering of living standards; moreover, guarding against the risks caused by ozone depletion requires simple but effective actions that can be performed by everyone, such as avoiding extended sun-exposure, or protecting oneself from the stronger UVB rays through sunscreens and sun glasses (Ungar 1998, 2000). What is relevant is that this behavioural response was grounded in the understanding of causal passages leading from individual behaviour to ozone depletion (hence the boycott of CFC-based products), and from ozone depletion to potential harms on the individual (hence the increased protection against the sun).

It is worth noting that the difference in the behavioural response to the ozone hole issue and climate change cannot be explained by higher media coverage of the first in comparison to the second: as the studies of $\operatorname{Ungar}(1988,2000)$ show, climate change attracted twice as many stories as ozone depletion did on the evening news broadcasts of the three major U.S. television networks, the same amount of coverage in the New York Times, and finally climate change averaged more than twice as many congressional hearings and publications as did ozone depletion (Ungar 2000, 304).

\subsection{Orone depletion's scientific explanation. Public perception and reaction}

As Figure 4 below shows, the series of events that leads to creation of the ozone hole, and consequently to potential harm on humans is, at first sight, much shorter than the series of causal passages leading to climate change. This does not imply that the scientific explanation of ozone depletion is also simpler - the chemical reactions that cause the destruction of ozone atoms are certainly not understandable to a wide audience.

However, the following can be immediately noticed. First, one does not need to have a full understanding of the science behind the causal passages for comprehending how the mechanism of ozone depletion broadly works. Second, the dynamics leading to ozone depletion are easier to represent cognitively and visually, with the image of a screen surrounding the Earth that is meant to protect it from UVB rays, but is unable to because it is damaged (Ungar 1998, 2000), and this makes the overall understanding much easier.

In contrast to climate change, there are no specific surveys for assessing public perception and understanding of the ozone hole issue on an international level. There are, however, a lot of smaller scale studies in the field of science education that are run in high schools, that may shed light on the issue. A Swedish field research project by Andersson and Wallin (2000) showed that high school students easily understood that there was an ozone barrier protecting the Earth, and that its thinning caused decreased protection from sun radiation. Students were confused about what ozone was, but had grasped the main concepts - the thinning of the layer and the risks it raised. 


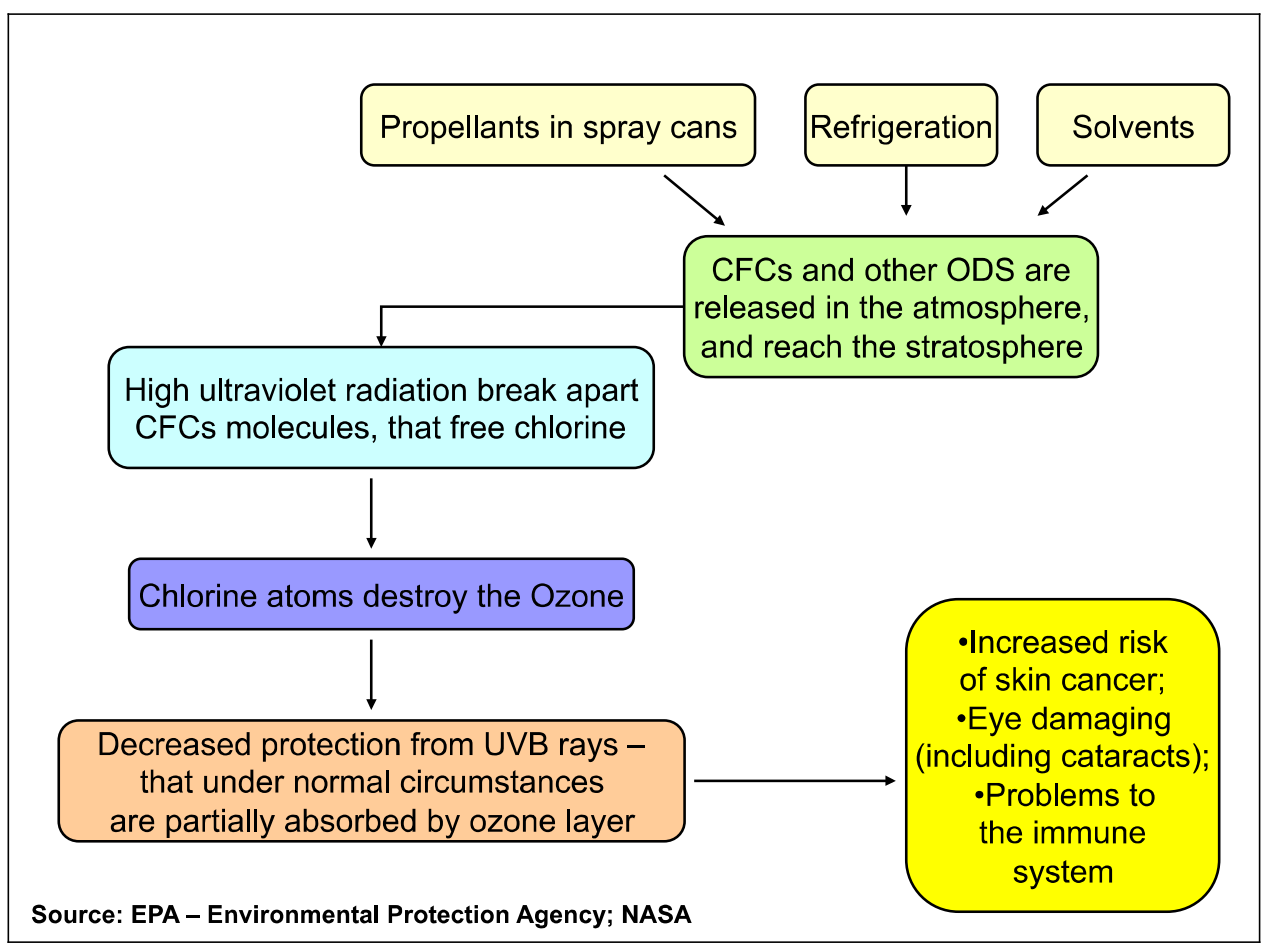

Figure 4: Ozone depletion

According to Andersson and Wallin, the ozone-layer model "fits in well with everyday experience - less resistance makes it easier to get through" (p.14), and requires less information to be understood than the greenhouse effect, which rather requires "quite a number of scientific concepts, including radiation, wavelength, the conservation of energy and steady state" (p.14). Also Boyes and Stanisstreet $(1994,1998)$ had previously reported similar results in a UK high school: a high percentage of students (three quarters, aged 13-14) were aware that the thinning of the ozone layer increases the risk of skin cancer (Boyes and Stanisstreet 1998). In a previous study, conducted with pupils aged 11 to 16, Boyes and Stanisstreet (1994) also showed that $80 \%$ of students (from a total of 1701 pupils) knew that CFCs damaged the ozone layer; as concerns the risks caused by ozone depletion, $70 \%$ of the youngest students (aged 11-12) and $90 \%$ of the oldest (aged 15-16) were aware that the thinning of the ozone layer would increase UV radiations' intensity and therefore skin cancer's likelihood.

In agreement with the survey results, the behavioural response to ozone depletion supports the claim that the essential facts concerning to the process of ozone depletion were comprehended by most people. As reported by Liftin (1994), according to UNEP data from the 1991 Report of the Technology and Economic Assessment Panel, between 1986 and 1991 there was a significant drop in CFC consumption by consumers, so that a 50\% target of decrease in CFC consumption could be reached by 1992 instead of 1995 - as the Protocol had established. In 1987, the Washington Post reports, 
in Berkeley, California, a boycott of Styrofoam (made with CFC) packaging, and a group of activists convinced McDonald's to stop using CFC-made Styrofoam (Liftin 1994). In Europe, in 1988 the European Environmental Bureau and the European Bureau of Consumers' Union threatened to organize a boycott if industry had not reduced CFC production to meet the Montreal Protocol's reduction target $-85 \%$ on CFC production (Jachtenfuchs 1990).

As concerns the risk of skin cancer, people have proven to be quite well aware of the risk of excessive sun-exposure. An Italian survey demonstrated that over $90 \%$ of interviewees between 16 and 22 years old knew that sun rays were harmful to the skin, and over $50 \%$ of them could specify the kind of damage they could produce (Monfrecola et al. 2000). Awareness of skin cancer has increased together with the incidence of melanoma - increased by 270\% from 1973 to 2002 (Markovic et al. 2007). Successful awareness campaigns have been conducted, such as, in Australia, the "Slip! Slop! Slap!" from 1980 to 1988 and the "SunSmart" campaign from 1988 to 2000 (Montague et al. 2001), or the "Sun How" campaign in Great Britain (Stott 1999), that all gave rise to a good degree of knowledge of the risks raised by sun radiation also due to ozone depletion (Stott 1999).

Two studies based in Australia (Marks 1994, Wright 1994) have reported a noteworthy growth in sunscreen sales (Wright 1994) and in general of protective behaviour, with a significant decrease of sunburns (Marks 1994), together with some structural changes such as removal of sales taxes from sunscreens (Marks 1994), and the provision of infrastructure for protecting against sun rays, like for example the development of shady areas (Marks 1994, and also Koh and Geller, 1998, with a US-based study). In general, interviewees of the studies reported knowing the importance of protecting against sun rays, and actually did it, mainly through the use of sunscreens (Stott 1999, Marks 1994, Wright 1994).

\section{Conclusion}

This paper does not pretend to claim that the simple cognition of causal relations within climate science would be able to produce a significant behavioural change, since knowledge is just one element, although a necessary one, of every decision process. Many of the above mentioned "pro-environment behaviours" simply imply sacrifices that people for other reasons are not willing to make - most often because of the change of habits they require, which are to some extent perceived as lowering living standards; or due to a lack of information on how to take action in the local context, or because of other kinds of interests involved that make fighting climate change not appealing.

What I argue is that most times a psychological excuse for not taking a specific action is also thinking that the action is not important or relevant for the desired purpose. The miscomprehension of the role of $\mathrm{CO} 2$ emissions in contributing to anthropogenic climate change is an easy path for dismissing the problem, and going on with business as usual. Identifying the main causes of a problem leads at least to an increased awareness of the impact of one's own actions. And this makes the denial and the dismissal psychologically more difficult. If, on the other hand, people are not able 
to identify the causes of a problem (either because they think that everything is potentially harmful, or that notbing is harmful), the result is the same: apathy.

The aim of this study was to show the importance of isolating the basic causal relations needed for taking action within a complicated issue such as climate change, and of improving communication in that direction. An understanding of causal dynamics would, at the very least, make it possible to take a correct preventive action - provided that individuals care to do so.

\section{REFERENCES}

Andersson, B., Wallin, A. 2000. Students' Understanding of the Greenhouse Effect, Societal Consequences of Reducing CO2 Emissions and Why Ozone Layer Depletion is a Problem. Journal of Research in Science Teaching, 37(10): 1096-1111.

Barrett, S. 2003. Environment \& Statecraft. The Strategy of Environmental Treaty-Making, Oxford University Press.

Benedick R.E. 1998. Orone diplomacy: new directions in safeguarding the planet, Harvard University Press.

Besson, U. 2008. Calcolare e capire: modelli formali e spiegazioni causali nella scienza, nel pensiero comune e nell'insegnamento della fisica. Giornale di Fisica, 49, 3: 161-193.

Bostrom, A., Granger Morgan, M., Fischhof, B., Read, D. 1994. What Do People Know About Global Climate Change? - 1. Mental Models. Risk. Analysis, 14, 6: 959-970.

Boyes, E., Stanisstreet, M. 1994. The ideas of secondary school children concerning ozone layer damage. Global Environmental Change, 4, 4: 311-324.

Boyes, E., Stanisstreet, M. 1998. High school students' perceptions of how major global environmental effects might cause Skin Cancer. The Journal of Environmental Education, 29, 2: 31-36.

Boykoff, M.T., Rajan, S.R. 2007. Signals and noise. Mass-media coverage of climate change in the USA and the UK. Science \& society - European Molecular Biology Organization Reports, 8, 3: 207-211.

Crate, S.A., Nuttal, M. (eds.) 2008. Anthropology and Climate Change: From Encounters to Actions, Walnut Creek, CA: Left Coast Press.

EPA [Environmental Protection Agency], Ozone Layer Protection, available at: http://www.epa.gov/ozone/strathome.html [accessed on May 1, 2012].

Eurobarometer surveys. Special Eurobarometer 300, 2008. Europeans' attitude towards climate change, Report. September 2008; http://ec.europa.eu/public_opinion/archives/ebs/ebs_300_full_en.pdf [accessed on May 1, 2012]

- Special Eurobarometer 322, 2009a. Europeans' attitude towards climate change, November 2009; available at: http://ec.europa.eu/public_opinion/archives/ebs/ebs_322_en.pdf [accessed on May 1, 2012]

- Standard Eurobarometer 72, 2009b. Public Opinion in the European Union, Report. Fieldwork OctoberNovember 2009; available at: http://ec.europa.eu/public_opinion/archives/eb/eb72/eb72_vol1_en.pdf [accessed on May 1, 2012]

- Standard Eurobarometer 72, 2009c Public Opinion in the European Union, First results, December 2009; available at: http://ec.europa.eu/public_opinion/archives/eb/eb72/eb72_first_en.pdf [accessed on May 1, 2012]

European Commission, Climate action. What's causing climate change? available at: http://ec.europa.eu/clima/policies/brief/causes/index_en.htm [accessed on May 1, 2012]

IEA [International Energy Agency], $\mathrm{CO}_{2}$ Emissions from Fossil Fuel Combustion, 2010 Edition, available at: http://www.iea.org [accessed on May 1, 2012].

IPCC [Intergovernmental Panel on Climate Change], Fourth Assessment reports. 2007. Working Group I: The Physical Science Basis. The IPCC Assessment of Climate Change and Uncertainties, available at http://www.ipcc.ch/publications_and_data/ar4/wg1/en/ch1s1-6.html\#box-1-1 [accessed on May 1, 2012]. 
- Climate Change 2007: Synthesis Report - Summary for Policymakers (Working Groups I, II, III). Available at: http://www.ipcc.ch/publications_and_data/ar4/syr/en/spm.html [accessed on May 1, 2012].

Jachtenfuchs, M. 1990. The European Community and the Protection of the Ozone Layer. Journal of Common Market Studies, 28, 3: 261-277.

Kahan, D.M., Peters, E., Braman, D., Slovic, P., Wittlin, M., Larrimore Ouellette, L., Mandel, G. 2011. The Tragedy of the Risk-perception Commons: Culture Conflict, Rationality Conflict, and Climate Change. Cultural Cognition Project Working paper No. 89.

Koh, H.K., Geller, A.C. 1998. Public Health Interventions for Melanoma: Prevention, Early detection, and Education. Hematology/Oncology Clinics of North America, 12, 4: 903-928.

Leiserowitz, A., Maibach, E., \& Roser-Renouf, C. 2010a. Global Warming's Six Americas, January 2010. Yale University and George Mason University. New Haven, CT: Yale Project on Climate Change.

Leiserowitz, A., Smith N. 2010b. Knowledge of Climate Change Across Global Warming's Six Americas, Yale University. New Haven, CT: Yale Project on Climate Change Communication.

Leiserowitz, A., Maibach, E., Roser-Renouf, C. \& Smith, N. 2010c. Americans' Actions to Conserve Energy, Reduce Waste, and Limit Global Warming: June 2010. Yale University and George Mason University. New Haven, CT: Yale Project on Climate Change Communication.

Litfin, K.T. 1994. Ozone Discourses. Science and Politics in Global Environmental Cooperation, New York: Columbia University Press.

Marks, R. 1994. Melanoma Prevention: Is It Possible to Change a Population's Behavior in the Sun? Pigment Cell Research, 7, 2: 104-106.

Markovic et. al. 2007. Malignant Melanoma in the 21st Century, Part 1: Epidemiology, Risk Factors, Screening, Prevention, and Diagnosis. Mayo Clinic Proceedings, 82(3): 364-380.

Mises, L. von. 1963. Human Action. A Treatise on Economics, San Francisco: Fox \& Wilkes, (1 ${ }^{\text {st }}$ ed. 1949, ed. by Yale University).

Monfrecola, G., Fabbrocini, G., Posteraro, G., Pini, D. 2000. What do young people know about the dangers of sunbathing, skin cancer and sunbed? A questionnaire survey among Italians. Photodermatology, Photoimmunology, Photomedicine, 16: 15-18.

Montague, M., Borland, R., Sinclair, C. 2001. Slip! Slop! Slap! and SunSmart, 1980-2000: Skin Cancer Control and 20 Years of Population-Based Campaigning. Health Education and Behavior, 28, 3; 290-305.

Norgaard, K.M. 2006. 'People Want to Protect Themselves a Little Bit': Emotions, Denial, and Social Movement Non participation. Sociological Inquiry, 76: 372-396.

Norgaard, K.M. 2009. Cognitive and Behavioral Challenges in Responding to Climate Change, Policy Research Working Paper 4940, The World Bank, Development Economics, World Development Report Team.

O’Neill, S., Nicholson-Cole, S. 2009. "Fear won't do it. Promoting Positive Engagement With Climate Change Through Visual and Iconic Representations. Science Communication, 30, 3: 335-379.

de Regt H.W., Dieks, D. 2005. A contextual approach to scientific understanding. Synthese 144: 137-170.

Read, D., Bostrom, A., Granger Morgan, M., Fischhof, B., Smuts, T. 1994. What Do People Know About Global Climate Change? - 2. Survey Studies of Educated Laypeople. Risk Analysis, 14, 6: 971982.

Reynolds, T.W., Bostrom, A., Read, D., Granger Morgan, M. 2010. Now What Do People Know About Global Climate Change? Survey Studies of Educated Laypeople, Risk Analysis, 30, 10: 1520-1538.

Salmon, W.C. 1984. Scientific Explanation and the Causal Structure of the World, Princeton University Press.

Stamm K.R., Clark, F., Reynolds Eblacas, P. 2000. Mass communication and public understanding of environmental problems: the case of global warming. Public Understanding of Science, 9: 219-237.

Stott, M.A. 1999. Tanning and sunburn: knowledge, attitudes and behaviour of people in Great Britain. Journal of Public Health Medicine. 21, 4: 377-384.

Strauss, S. 2008. Global Models, Local Risks: Responding to Climate Change in the Swiss Alps. In Anthropology and Climate Change: From Encounters to Actions, eds. S.A. Crate, M, Nuttal. Walnut Creek, CA: Left Coast Press.

UNEP (United Nations Environment Programme), 2010 Assessment Report of the Halons Technical Options Committee; Montreal Protocol On Substances that Deplete the Ozone Layer. Available at: http://ozone.unep.org/Assessment_Panels/TEAP/Reports/HTOC/index.shtml 
Ungar, S. 1988. Bringing the Issue Back In: Comparing the Marketability of the Ozone Hole and Global Warming. Social Problems, 45: 510-527.

Ungar, S. 2000. Knowledge, ignorance and the popular culture: climate change versus the ozone hole. Public Understanding of Science, 9: 297-312.

Wåhlberg, A.A., Sjöberg, L. 2000. Risk perception and the media. Journal of Risk Research, 3, 1: 31-50.

Wilson, K.M. 2000. Communicating Climate Change through the Media. Predictions, politics and perception of risks. In Environmental riskes and the media, eds. S. Allan, B. Adam, C. Carter, London: Routledge. Wright, B. 1994. Sunscreens and the protection racket. New Scientist, 141, 1909: 21-22.

Francesca Pongiglione completed a post-doctoral fellowship at the University of Bologna, where she received a PhD in Ethics. She is currently a PhD fellow in Neuroscience of Decision-making at the University Vita-Salute San Raffaele, Milano. Her research focuses on decision theory.

AddRess: Università Vita-Salute San Raffaele, Facoltà di Filosofia, Via Olgettina 58, 20132 Milano, Italy. E-mail: francesca.pongiglione@unibo.it 